\title{
SESENTA AÑOS DE LA LEY FUNDAMENTAL ALEMANA - DE UN PROVISORIO CON UNA LARGA VIDA
}

\section{Sixty years German Basic Law - about a long living provisional solution}

RESUMEN: Originalmente pensada como una constitución provisoria, la Ley Fundamental alemana se encuentra en vigor desde hace sesenta años y durante este tiempo ha ganado reputación a nivel nacional e internacional. A través del presente artículo se analizan el surgimiento y el desarrollo de la Ley Fundamental, los fundamentos de su éxito, el rol del Tribunal Constitucional Federal y su estado actual.

PALABRAS CLAVE: Ley Fundamental, Alemania, historia constitucional, derechos fundamentales

ABSTRACT: Intended as an interim solution the German constitution, the Basic Law, has been in force for sixty years. Having gained reputation on a national and international level this article analyzes the emergence and development of the Basic Law, the reason for its success, the role of the Federal Constitutional Court and its contemporary status.

KEY WORDS: Basic Law, Germany, constitutional history, basic rights

AGRADECIMIENTOS: A la abogada Tamara Tijerino por la corrección del texto y el apoyo lingüístico.

El autor es Doctor de la Universidad de Hamburgo, Alemania, Magister legem de la University of New South Wales, Sydney, Australia. Actualmente es Profesor invitado de la Universidad de Chile y de la Universidad de Heidelberg, Heidelberg Center para América Latina. 


\section{A. INTRODUCCIÓN}

La Ley Fundamental o "Grundgesetz"2 entró en vigor el 23 de mayo de 1949 como la llamada constitución de la República Federal de Alemania, ${ }^{3}$ también conocida, en aquella época, como Alemania Occidental. La Ley Fundamental ha comprobado ser un éxito y ha ganado mucha reputación tanto a nivel nacional como internacional a lo largo de los años; y es con orgullo que se celebra actualmente su aniversario. Esta Ley Fundamental fue originalmente considerada una constitución provisoria, pero desde entonces han pasado 60 años; por tanto, lo que fue concebido como una solución temporal a los problemas de la época ha evolucionado de tal manera que hoy es considerada la constitución más liberal, exitosa y estable de la historia alemana. Este acontecimiento conlleva a algunas interrogantes: ¿En qué se basa este éxito? ¿Cuáles son las razones de la estabilidad y del reconocimiento de esta constitución?

Las causas son numerosas: Entre ellas se encuentra el amargo recuerdo del Tercer Reich. Basándose en este momento histórico tan traumático para Alemania, se desarrolla el deseo de un estado social-demócrata con énfasis en el estado de derecho. Otra razón que conlleva al éxito de esta constitución -aunque es una razón material mas no política ni jurídica- es el enorme avance económico que había logrado Alemania Occidental. Un aspecto aún más significativo que los anteriores es el enfoque a la protección y garantía de los derechos humanos que concede la Ley Fundamental alemana. El aspecto central de la Ley Fundamental es el ser humano.. ${ }^{4}$ Las garantías conferidas en esta constitución, en relación a los derechos fundamentales de los seres humanos, han permitido el libre y protegido desarrollo de los intereses y habilidades de ellos. Un factor trascendental en este contexto ha sido que los derechos fundamentales otorgados mediante la Ley Fundamental han sido diseñados como derechos subjetivos exigibles en los tribunales independientes; es decir, que la protección de los derechos fundamentales va mucho más lejos que la mera formulación de principios generales o buenas intenciones.

Apoyado por un fuerte y alerta Tribunal Constitucional, el amplio catálogo de los derechos fundamentales - con el tiempo- se ha ganado una gran importancia en todas las áreas del derecho y en la vida del ciudadano. Casi no existe ninguna materia dentro del derecho alemán que no esté influenciada de alguna manera por los derechos fundamentales; no existe un jurista que no tome en consideración estos derechos para solucionar los casos comunes en materias penales, familiares, de arriendo, de cons-

2 La abreviación utilizada generalmente en la República Federal de Alemania es "GG".

3 Alemania es un estado federal; en consecuencia, existen dos clases de constituciones, las de cada estado federado y la constitución de la federación. Esta última es la Ley Fundamental.

4 Compare el artículo 1 de la Ley Fundamental:

“(1) La dignidad humana es intangible. Respetarla y protegerla es obligación de todo poder público.

(2) El pueblo alemán, por ello, reconoce los derechos humanos inviolables e inalienables como fundamento de toda comunidad humana, de la paz y de la justicia en el mundo". 
trucción, entre otras materias. ${ }^{5}$ Por otro lado, existen pocos proyectos políticos importantes en los cuales no se utilizan los derechos fundamentales como argumento político en la discusión. ${ }^{6}$ A esto hay que agregar que los derechos fundamentales no sólo han sido usados como herramientas por juristas o políticos, sino que la concientización social ha crecido en tal medida que todos los ciudadanos han utilizado los mecanismos indicados para proteger sus derechos consagrados en la Ley Fundamental alemana. Es por eso, que los ciudadanos han tratado de defender sus libertades refiriéndose a sus derechos fundamentales ante los tribunales en ámbitos muy amplios hasta el derecho de alimentar a las palomas ${ }^{7}$ o el de cabalgar en el bosque. ${ }^{8}$ Esta concientización sobre las garantías constitucionales puede llegar a extremos: Poco después de la famosa sentencia del Tribunal Constitucional sobre el caso "Crucifijo" un ciudadano prohibió a un agente aduanero saludarle con un "Adiós" haciendo referencia al derecho fundamental de la libertad de creencia, argumento sobre el cual versaba dicha sentencia. ${ }^{10}$ Aunque puede considerarse un ejemplo absurdo, es un ejemplo que permite ilustrar la magnitud de los derechos fundamentales y de la Ley Fundamental en la conciencia de la ciudadanía.

\section{B. BASES HISTÓRICAS DE LA LEY FUNDAMENTAL}

\section{Introducción}

Se dice que para poder entender de forma completa una constitución es necesario conocer sus antecedentes históricos. Este dicho es totalmente cierto en el caso de la Ley Fundamental, porque ésta es, en gran parte, una reacción directa a las malas experiencias históricas; al malfuncionamiento de la República de Weimar que como consecuencia se desencadenó en el Tercer Reich, una dictadura de un terror y de mal que nunca antes había visto el mundo y que ojala nunca más se tenga que ver.

La Ley Fundamental fue desarrollada por el Consejo Parlamentario (Parlamentarischer Rat), el cual era un órgano constituido por 65 miembros nombrados por los gobiernos de los once estados federados de la Alemania Occidental, a instrucción del mando militar de las zonas de ocupación estadounidense, británica y francesa. A partir del 1 de septiembre 1948 el Consejo Parlamentario redactó la Ley Fundamental, la cual fue aprobada el 8 de mayo de 1949. El 12 de mayo esta Ley fue ratificada por los

5 Es por eso que algunos autores dicen que la "Bundesrepublik Deutschland” (República Federal de Alemania) se ha convertido en la "Grundrechtsrepublik Deutschland" ( República de los Derechos Fundamentales de Alemania), HufEn (1999), p. 1504.

6 Hufen (1999), p. 1505 con ejemplos.

7 Bundesverfassungsgericht (23.05.1980).

8 Bundesverfassungsgericht (06.06.1989); para ello RENNERT (1989), p. 3261; KunIG (1990), p. 523.

9 Bundesverfassungsgericht (16.05.1995), para ello BILETZKI (1996), p. 2633; RENCK (1996), p. 16; BADURA (1996), p. 71; StOlleIs (2000), p. 376.

10 Frankfurter Allgemeine Zeitung (1998). 
gobernadores militares y, poco después, por los parlamentos de los estados federados. ${ }^{11}$ La Ley Fundamental fue proclamada por el Consejo Parlamentario el 23 de mayo de 1949, entrando en vigor en las tres zonas de ocupación occidentales y en la parte occidental de Berlín.

La Ley Fundamental no se inventó en un tubo de ensayo; sino que fue el resultado del desarrollo de antecedentes históricos. ${ }^{12}$ La historia constitucional democrática de Alemania había sido corta antes de esta Ley, la cual es solamente la tercera constitución democrática alemana a nivel nacional. La primera, la Constitución de la Iglesia de San Pablo de Frankfurt de 1849, nunca entró en vigor, pero tiene importancia como modelo histórico, ${ }^{13}$ especialmente con respeto a los derechos fundamentales. Estos derechos ya habían jugado un rol importante en la Constitución de la Iglesia de San Pablo y es por eso que en un capítulo separado de esta constitución se garantizó como derechos fundamentales la libertad de las personas, de opinión, de reunión, la libertad científica, el secreto postal, la inviolabilidad de la propiedad, la libertad de circulación y la abolición de la pena de muerte, entre otros. Estos derechos fundamentales fueron copiados, en parte de forma literal, a las constituciones de Weimar y también a la Ley Fundamental.

La segunda constitución democrática alemana fue la Constitución de Weimar ${ }^{14}$ de los años 1919-1933. ${ }^{15}$ Esta constitución nunca tuvo el respaldo necesario de la población y, si se observa a la luz de la situación política de la época se puede determinar que contenía graves vicios. Es ampliamente conocido que fueron los problemas de esta Constitución una de las causas del quebrantamiento de la República de Weimar y de los trágicos acontecimientos sufridos en Alemania y el mundo en los años siguientes. Es por esta razón, que los padres de la Ley Fundamental, el Consejo Parlamentario, aunque usaron la Constitución de Weimar como modelo histórico la pretensión era evitar los vicios contenidos en ella en la nueva constitución bajo la idea de "Nunca más Weimar".

\section{Resultados de experiencias históricas}

Entre los vicios de la Constitución de Weimar que la Ley Fundamental trataba de evitar, se encontraba el desequilibrio entre los poderes de los diferentes órganos del

11 Solamente un estado, el estado de Bavaria, rechazó la ratificación de la Ley Fundamental después de 18 horas de debate turbulento pidiendo mayores competencias para los estados federados y un mejor anclaje de la iglesia en la Ley Fundamental. Sin embargo el "No" no fue un "No" absoluto, porque en la misma sesión se decidió que la Ley Fundamental igual entraría en vigor si dos tercios de los otros estados federados lo ratificaban. Un hecho que ya era seguro.

12 RottMann (1988), p. 10.

13 Vea en detalle KüHNE (1998).

14 El nombre correcto es "Constitución del Imperio Alemán", pero para distinguir esta constitución de la "Constitución del Imperio Alemán” de 1871, es generalmente denominada como Constitución de Weimar.

15 La Constitución de Weimar formalmente siguió en vigor después de la toma de poder de Hitler el 30 de enero de 1933. Sin embargo, materialmente fue derogada ampliamente por la ley para la eliminación de necesidad del pueblo y del Imperio alemán, más conocida como "Ermächtigungsgesetz" (Ley de autorización) del 23 de marzo 1933. Con la toma del control por el Consejo de Control Aliado el 5 de junio 1945 la Constitución de Weimar fue definitivamente obsoleta. 
estado. Uno de las problemas de la República de Weimar era que el presidente tenía amplios poderes ejecutivos. En especial en lo relacionado con el artículo 48 de la mencionada constitución, el cual le confería al presidente el poder de intervenir en situaciones excepcionales y tomar todas las acciones que considerase necesarias; esto incluía amplios poderes como promulgación de decretos-leyes (decretos de urgencia) y la suspensión de los derechos fundamentales. Este poder es considerado uno de los factores clave para el hundimiento de la República de Weimar. Debido a estos poderes otorgados en la constitución anterior, no es sorpresa que bajo la Ley Fundamental las funciones presidenciales sean, en su mayoría, representativas, y también que el poder gubernamental fuese fortalecido en la Ley Fundamental. El gobierno es responsable únicamente frente al Parlamento Federal ("Bundestag") y no ante el parlamento y el presidente, como era el caso en la República de Weimar. En la misma línea de estabilizar el gobierno, se encuentra la regla de la Ley Fundamental que establece que el Canciller Federal, el jefe del gobierno federal, una vez electo, solo puede ser destituido de su cargo durante el mismo período legislativo si el Parlamento Federal elige al mismo tiempo un nuevo Canciller Federal (voto de desconfianza constructivo). ${ }^{16}$ Este mecanismo ayudó a evitar lo que sucedió durante la República de Weimar, donde hubo 15 Cancilleres en 14 años.

Otra reacción a las experiencias sucedidas en Weimar es el desconocimiento de la Ley Fundamental de plebiscitos. ${ }^{17}$ Esta es una consecuencia al abuso del instituto de plebiscito por partidos extremistas como el partido nacionalsocialista para fines propagandistas durante la época de Weimar, y de la desconfianza de los aliados y del Consejo Parlamentario en el pueblo alemán. Otro resultado a los acontecimientos históricos es que las modificaciones que se deban de realizar de la Ley Fundamental -contrario a lo previsto en la Constitución de Weimar- deben de ser explícitas.

También la Ley Fundamental trata de "blindar" la esencia de la constitución democrática contra posibles avances de partidos totalitarios mediante una "cláusula de eternidad", ${ }^{18}$ que impide la modificación de la Ley Fundamental con respecto a la dignidad del ser humano, la organización estatal como un estado federal, democrático, social de derecho y con separación de poderes. El orden establecido por la Ley Fundamental está además protegido por un derecho a resistencia. ${ }^{19}$

16 Artículo 67 de la Ley Fundamental:

“(1) El Bundestag sólo podrá plantear una moción de censura frente al Canciller Federal si elige por mayoría de sus miembros a un sucesor y solicita del Presidente Federal el relevo del Canciller Federal. El Presidente Federal deberá acceder a esta solicitud nombrando a quien resulte elegido.

(2) Entre la moción y la votación deberán transcurrir cuarenta y ocho horas"; ver RotTMANN (1988), pp. 16 y ss.

17 La única excepción es el caso de la reorganización de los estados federados, por la cual se necesita la ratificación por referéndum (Artículo 29 inciso 2 Ley Fundamental). También algunas constituciones de los estados federados incluyen el instituto de plebiscito.

18 Artículo 79 inciso 3 de la Ley Fundamental: "No está permitida ninguna modificación de la presente Ley Fundamental que afecte la organización de la Federación en Länder, o el principio de la participación de los Länder en la legislación, o los principios enunciados en los artículos 1 y 20 ”.

19 Artículo 20 inciso 4 de la Ley Fundamental: "Contra cualquiera que intente eliminar este orden todos los alemanes tienen el derecho de resistencia cuando no fuere posible otro recurso". 
Tanto la Constitución de Weimar como la Ley Fundamental contienen un amplio catálogo de derechos fundamentales. La diferencia primordial entre los derechos fundamentales de la Constitución de Weimar y los de la Ley Fundamental es que en la Constitución de Weimar, éstos eran definiciones de los objetivos del estado, directrices para los órganos estatales, pero no un derecho obligatorio que confería derechos irrevocables a los ciudadanos ante la justicia. ${ }^{20}$ En contraposición a lo establecido anteriormente, en la Ley Fundamental los derechos fundamentales son derechos subjetivos exigibles ante los tribunales independientes. Los derechos fundamentales de la Constitución de Weimar solamente tenían efectos para el poder administrativo, pero no vinculaban al poder legislativo. Por el contrario, la Ley Fundamental vincula los derechos fundamentales como derechos directamente aplicables a los poderes legislativo, ejecutivo y judicial. ${ }^{21} \mathrm{El}$ establecimiento de derechos fundamentales otorga a todos los ciudadanos el derecho de reclamar ante la justicia estos derechos contra cualquier poder del estado; ésta es una fuerte respuesta de la Ley Fundamental a la dictadura nacionalsocialista del Tercer Reich. ${ }^{22}$ Esta réplica importante también se ha mostrado en el orden y la estructura de la Ley Fundamental; contrario a lo sucedido en la Constitución de Weimar, en la cual los derechos fundamentales se encontraban al final de la constitución en el libro II "Derechos y deberes fundamentales del ciudadano alemán”, es decir, en los artículos 109-165 de la mencionada constitución. En cambio, en la Ley Fundamental, estos derechos se encuentran al comienzo de la constitución, reflejando su rol primordial, y es de esta manera, que se hace visible la amplia protección de los derechos fundamentales en el núcleo de la Ley Fundamental. Para enfatizar este rol todavía más, el Artículo 1 de la Ley Fundamental establece: "La dignidad humana es intangible. Respetarla y protegerla es obligación de todo poder público".

Todos los ajustes anteriormente mencionados han sido fundamentales para evitar que se cometan los mismos errores dos veces, objetivo que ha sido un éxito hasta ahora y se espera que los errores del pasado no vuelvan a surgir. Es por eso que el dicho "Bonn no se volvió en Weimar, porque Weimar había existido” tiene mucho fundamento.

\section{III. "Ley Fundamental" en vez de "Constitución"}

La Ley Fundamental para la República Federal de Alemania ("Grundgesetz für die Bundeserepublik Deutschland”) es el nombre de la constitución de la República Federal de Alemania, que hasta la unificación en el año 1990 era conocida como Alemania Occidental. El Consejo Parlamentario utilizó la expresión “Ley Fundamental” en vez de "Constitución" para dejar claro el carácter provisional de ésta debido a la separación de Alemania y el deseo de que con la unificación, la Ley Fundamental como constitución provisional fuera substituida por una constitución decidida y adoptada por todo el pueblo alemán en libre decisión. ${ }^{23}$

\footnotetext{
20 Rottmann (1988), p. 12, ver también BüHLer (1931), pp. 111 y ss.

21 Artículo 1 inciso 3 de la Ley Fundamental.

22 RotTmann (1988), p. 13.

23 Compare artículo 146 de la Ley Fundamental: "La presente Ley Fundamental que, después de haberse
} 
Cuarenta años han pasado desde entonces y la unificación alemana se ha vuelto una realidad, pero la idea de substituir la Ley Fundamental por una nueva constitución no fue realizada. Este fenómeno se debió a la alta aceptación y reconocimiento que ha tenido esta Ley Fundamental por el pueblo alemán. Por lo tanto, la unificación se realizó formalmente mediante una adhesión de los cinco estados federados orientales al territorio de vigencia de la Ley Fundamental. Por la misma razón, tampoco se ha cambiado el nombre de Ley Fundamental de la República Federal de Alemania a Constitución de la República Federal de Alemania.

\section{La Ley Fundamental de 1949 hasta hoy}

Desde 1949, la Ley Fundamental ha sido modificada 54 veces. Entre las reformas más importantes se encuentran: el rearme y la creación de las Fuerzas Armadas Federales en 1956 junto con el servicio militar obligatorio; la modificación a la llamada Constitución para el Caso de Emergencia que permitía restricciones a los derechos civiles en caso de guerra (1968) y una reorganización del derecho constitucional financiero. Durante los años setenta y ochenta la Ley Fundamental no recibió cambios importantes. Los años noventa fueron caracterizados por la unificación de los dos estados alemanes y el anclaje constitucional del proceso de integración europeo. Aunque la unificación se realizó formalmente mediante una adhesión de los cinco estados federados orientales al territorio de vigencia de la Ley Fundamental, la reunificación produjo algunos cambios en la Ley Fundamental, debido al Tratado de Unificación del año 1990 y la reforma constitucional del año 1994. En el año 2006, en la llamada Reforma Federal, se hicieron las modificaciones más grandes en la historia de la Ley Fundamental ${ }^{24}$ reorganizando las competencias entre el Estado federal y los estados federados.

Con respeto a los derechos fundamental cabe destacar la limitación realizada en relación al derecho al asilo político en el año $1993,{ }^{25}$ la llamada vigilancia secreta en gran escala (Grosser Lauschangriff) ${ }^{26}$ del año 1998 y algunos cambios causados por la integración europea y la creación de la Corte Penal Internacional en el año 2000. ${ }^{27}$

\section{ROL DEL TRIBUNAL CONSTITUCIONAL FEDERAL}

Impreso en papel de tamaño A4 la Ley Fundamental pesa alrededor de 126 gramos. Queda la pregunta: ¿En qué se funda la diferencia entre la protección efectiva de los derechos fundamentales y 126 gramos de papel con tinta? En la aceptación de la

consumado la unidad y la libertad de Alemania, es válida para todo el pueblo alemán, perderá su vigencia el día en que entre en vigor una Constitución que hubiere sido adoptada en libre decisión por todo el pueblo alemán".

24 En esta reforma 25 artículos de la Ley Fundamental fueron cambiados, insertados o borrados.

25 Ver artículo 16a Ley Fundamental.

26 Ver artículo 13 Ley Fundamental.

27 En detalle SACHS (2009), pp. 1441 y ss. 
constitución por todas las instituciones del Estado y por los ciudadanos. En el caso de Alemania también el Tribunal Constitucional Federal juega un rol importante. Existe mucha verdad tras lo mencionado por algunos comentaristas sobre que la Ley Fundamental sin el buen espíritu del Tribunal Constitucional Federal no valdría ni el papel en que está impresa. ${ }^{28}$

Durante los últimos 58 años $^{29}$ el Tribunal Constitucional Federal ha cuidado e interpretado la Ley Fundamental. Con su trabajo el Tribunal Constitucional ha dado vida a la Ley Fundamental y ha fortificado la reputación de ésta. En la práctica la Ley Fundamental se encuentra en vigor en la forma en la cual el Tribunal Constitucional Federal lo interpreta. ${ }^{30}$ Por lo tanto, la historia de la Ley Fundamental es al mismo tiempo la historia de la jurisprudencia del Tribunal Constitucional Federal. ${ }^{31}$

El Tribunal Constitucional Federal es una institución característica de la actual democracia alemana. Su tarea, como máximo guardián de la constitución, es asegurar que todas las instituciones estatales cumplan la Ley Fundamental y que los ciudadanos no sean privados de sus derechos fundamentales, los cuales fueron garantizados en la Ley Fundamental. Al mismo tiempo, el Tribunal Constitucional Federal tiene el monopolio de interpretación de esta Ley.

El Tribunal Constitucional Federal está compuesto por dos senados. Cada uno de ellos tiene ocho miembros nombrados por un período de 12 años. De cada senado, cuatro miembros son elegidos por el Parlamento Federal ("Bundestag") y los otros cuatro por el Consejo Federal ("Bundesrat”). Para la elección de un juez del Tribunal Constitucional Federal se necesita una elevada mayoría de dos tercios, lo que hace necesario que el partido político mayoritario haga compromisos con la oposición. Con este mecanismo y con la exclusión de la reelección de los jueces se busca garantizar la independencia política y la imparcialidad de los jueces.

La función del Tribunal Constitucional Federal es ser guardián de la constitución. Sin embargo, el Tribunal Constitucional Federal sólo puede actuar si se promueve un recurso ante él. Entre estos recursos se encuentren las disputas constitucionales entre distintos órganos estatales federales o entre el Estado federal y los estados federados. El Tribunal Constitucional Federal también tiene el monopolio en la declaración de inconstitucionalidad de partidos políticos y de una ley. Con respeto a lo último, el control de constitucionalidad de una ley se distingue entre el control normativo concreto y el abstracto. El control normativo concreto revisa la constitucionalidad de una ley a solicitud de las

\footnotetext{
28 LAMPRECHT (2009), p. 1454.

29 El Tribunal Constitucional, aunque previsto en la Ley Fundamental (artículos 92-94) no fue constituido cuando la Ley Fundamental entró en vigor. Para su constitución fue necesario una ley especial, la Ley Orgánica del Tribunal Constitucional. Con esta en vigor, el Tribunal Constitucional Federal fue formado el 28.9.1951.

30 SMEND (1962), p. 24.

31 LAMPRECHT (2009), p. 1454.
} 
cortes ordinarias, si éstas tienen dudas de la constitucionalidad de una ley aplicable a un litigio concreto frente de ellas. El control normativo abstracto se refiere a la revisión de constitucionalidad de las leyes regularmente aprobadas dentro del proceso legislativo democrático a solicitud del Gobierno Federal; del gobierno de un estado federado o de al menos el 30\% de los miembros del Parlamento Federal. Es importante destacar que todos estos recursos, aunque son de gran importancia para el funcionamiento del estado, solamente equivalen al 3\% de los casos del Tribunal Constitucional Federal.

El otro $97 \%$ de los casos se refieren al recurso del amparo constitucional. ${ }^{32}$ Bajo este recurso cualquier persona (incluyendo personas jurídicas y extranjeros) que se crea lesionado en sus derechos fundamentales por acciones estatales (ejecutivas, legislativas o jurídicas) puede dirigirse al Tribunal Constitucional Federal para defender sus derechos. ${ }^{33}$ Este porcentaje demuestra la importancia de la protección de los derechos fundamentales en general; la conciencia de los ciudadanos por sus derechos constitucionales y la efectiva protección procesal de ellos, pero también refleja el rol importante del Tribunal Constitucional en la protección de los derechos fundamentales.

A pesar de esto, el Tribunal Constitucional Federal no tenía esta posición y esta reputación sobresaliente desde sus comienzos. ${ }^{34} \mathrm{Al}$ fundarse, este Tribunal tuvo que luchar para ser aceptado a la misma altura de los otros órganos políticos, especialmente por el Gobierno Federal. Hoy en día esto ha cambiado, y se debe al reconocido trabajo del Tribunal durante los últimos 58 años que los ciudadanos confían más en el Tribunal Constitucional Federal que en sus políticos, ${ }^{35}$ reflejándose de esta manera los logros del Tribunal.

Cuando el Tribunal Constitucional empezó su trabajo en la República Federal de Alemania, el país se encontraba jurídicamente en desarrollo y continuó siendo así por muchos años. ${ }^{36}$ En aquel entonces, la percepción de los derechos fundamentales como derechos subjetivos $-y$ también como práctica- exigibles era algo nuevo para el pueblo. Es por eso que se ha necesitado de tiempo para ganarse la confianza de los ciudadanos y poder llegar a su conciencia, estableciendo qué es lo que significa vivir en un estado de derecho protegido por derechos fundamentales. ${ }^{37}$

32 Anualmente se registran 6.000 amparos constitucionales. De estos un 2,5\% es exitoso, lo que significa que el Tribunal Constitucional Federal considera que los derechos fundamentales han sido violados unas 150 veces, aproximadamente, cada año corrige el significativo número de 150 violaciones de los derechos fundamentales.

33 El amparo constitucional tiene varias condiciones de admisibilidad, compare el artículo 93 inciso 1 $\mathrm{N}^{\circ}$ 4a Ley Fundamental, $\S \S 13$ № 8a, 90-96 Ley Orgánica del Tribunal Constitucional.; al detalle ZucK (2006), pp. 127 y ss.

34 Detjen (2009), p. 5; LAMPRECHT (2009), pp. 1454 y ss.

35 Similar el Presidente del Parlamento Federal LAMMERT (2009).

36 LAMPRECHT (2009), pp. 1456 y ss.

37 Hasta hoy tiene algo de popularidad el chiste de humor negro, supuestamente de Winston Churchill, diciendo que "democracia es cuando tocan el timbre de la puerta a las 6 de la mañana y uno puede estar seguro que es el lechero"; que en esta nueva época, después del terror del Tercer Reich, describe adecuadamente la nueva percepción de la gente, compare LAMPRECHT (2009), p. 1456, también DeTJEN (2009), pp. 5 y ss. 
Por otro lado, se ha demorado muchos años hasta que las leyes materiales han logrado ser más conformes con las normas constitucionales, especialmente en lo relacionado con los derechos fundamentales. No cuesta mucho nombrar un par de ejemplos para clarificar este punto: Hijos ilegítimos que esperaban 20 años a su equiparación; la igualdad de derechos era una utopía para las mujeres como, por ejemplo, que la representación de los hijos estaba en la figura paterna hasta 1979; los homosexuales eran discriminados y amenazados con penas de privación de libertad; ${ }^{38}$ escuelas y universidades que insistieron que sus decisiones en exámenes no fueron justiciables; ${ }^{39}$ hasta el año 1993 el Código Civil también preveía la obligación de pagar daños morales por la pérdida de virginidad durante el compromiso matrimonial que no se cumplió; ${ }^{40}$ padres de hijos mayores de edad que permitieron que su hijos durmiesen con su pareja del otro sexo bajo el mismo techo fueron criminalizados por alcahuetería. ${ }^{41}$

Estos ejemplos muestran el largo camino en la implementación real de los derechos fundamentales y la importancia que tuvo el Tribunal Constitucional Federal durante este período para lograrlo.

\section{TENDENCIAS NEGATIVAS}

\section{Abuso del Tribunal Constitucional como continuación de política con otros medios}

En las últimas décadas se ha podido observar una tendencia de abuso del Tribunal Constitucional Federal por políticos o partidos políticos como continuación de su política con otros medios. Si estos partidos políticos no han tenido la suficiente mayoría por su opinión política en el Parlamento Federal han tratado de probar suerte al buscar una mayoría en el Tribunal Constitucional Federal. ${ }^{42}$

Existe una línea fina entre política y derecho constitucional. Muchas veces no se puede separar por completo el uno del otro. Por lo tanto, es importante que el Tribunal Constitucional Federal se enfoque en lo jurisdiccional. En general, el Tribunal Constitucional Federal ha practicado en sus decisiones el "judicial self-restraint", aunque no queda duda que en algunas decisiones un poco más del "judicial self-restraint" hubiera sido mejor. ${ }^{43}$

38 §§ 175, 175a Código Criminal versión antigua, reformado 1969 y 1973, abrogado el 23.11.1973.

39 Compare la sentencia directiva del Tribunal Constitucional Federal, Bundesverfassungsgericht (17.04.1991).

40 Amtsgericht Münster (08.12.1992); Bundesverfassungsgericht (05.02.1993); compare también Bundesverfassungsgericht (26.01.1972).

$41 \S 180$ Código Criminal versión antigua, abrogado el 23.11.1973.

42 LAMPRECHT (2009), p. 1456.

43 LAMPRECHT (2009), p. 1456 con ejemplo. 
Por el otro lado, la política debería decidir los asuntos políticos y no transferir la decisión de éstos al Tribunal Constitucional Federal disfrazando estos asuntos de preguntas jurídicas. Parece que es una actitud tentativa, especialmente si se trata de decisiones poco populares, porque ofrece la posibilidad de colgarle al Tribunal Constitucional Federal el sambenito y, al mismo tiempo, lavarse las manos frente a los electores. Pero con una actitud así se corre el riesgo de desequilibrar el sistema institucional. ${ }^{44}$

\section{Deformación del texto de la Ley Fundamental}

La Ley Fundamental ha estado en vigor por más de 60 años. Durante este tiempo se le han realizado 54 modificaciones, algunas de ellas transcendentales. ${ }^{45}$ Es difícil decidir si 54 cambios son muchos o pocos. Por un lado, son más reformas de las que ha tenido la Constitución de los Estados Unidos en 200 años, por otro lado, equivale a menos de una modificación por cada año que ha transcurrido ${ }^{46}$ y en comparación a otras constituciones no es un número elevado. Sin duda, el desarrollo de la Ley Fundamental fue necesario, es necesario y también será necesario en el futuro.

Desafortunadamente, muchos de los cambios que se realizaron en cuanto a la forma, en especial los relacionados con los derechos fundamentales, no fueron exitosos. Frecuentemente, estos cambios produjeron que la constitución quedase con más fallos que antes. ${ }^{47}$ Mientras que el texto original parecía una obra de arte, las nuevas formulaciones son largas, detalladas, complejas y feas. ${ }^{48} \mathrm{El}$ texto de la Ley Fundamental ahora tiene el doble de su tamaño original. ${ }^{49}$ Para dar un ejemplo: La clara y impresionante frase que los padres de la Ley Fundamental incluyeron en un mundo lleno de refugiados, el antiguo artículo 16 inciso 2 frase 2 de la Ley Fundamental que establecía que: "Perseguidos políticos gozan asilo", frase que fue cambiada y limitada por un monstruo jurídico de alrededor de 300 palabras. ${ }^{50}$ Lo mismo pasó con el artículo 13 de la Ley Fundamental que garantiza la inviolabilidad del domicilio. ${ }^{51}$ Los cambios se asemejan a la construcción de un edificio de 25 pisos en una ciudad colonial o como dice otro comentador equivale a un "edificio garaje hecho de hormigón en un conjunto de Bauhaus. ${ }^{52}$ Esto no es primariamente un problema estético; ${ }^{53}$ sino que el edificio de 25 pisos o el edificio garaje conllevan con ellos problemas estructurales. Se pierde el espíritu abierto y la flexibilidad que han hecho posible una interpretación y adapta-

44 Compare Lamprecht (2009), p. 1456 con ejemplos históricos de la República de Weimar.

45 SACHS (2009), p. 1441.

46 LAMMERT (2009).

47 MÖllers (2009), p. 7.

48 MÖllers (2009), p. 7; PAPIER (2009): locuaz“.

49 LAMMERT (2009).

50 Articulo 16a Ley Fundamental, entrando en vigor el 30 de junio de 1993.

51 Compare la crítica del actual presidente del Tribunal Federal Constitucional PAPIER (2009).

52 MÖllers (2009), p. 7.

53 LIMBACH (2009). 
ción a los cambios sociales y de hecho y a los nuevos desafíos que ha traído consigo el futuro. ${ }^{54}$ Mientras los reglas antiguas después de 60 años todavía parecen jóvenes y actuales, muchas de las normas recién insertadas parecen ya desfasadas. ${ }^{55}$

El problema de fondo es que para poder cambiar la Ley Fundamental, generalmente es necesario un compromiso entre los otros grandes partidos políticos. ${ }^{56}$ Estos compromisos tienen la tendencia de impedir un reglamento simple. Los detalles del compromiso merecen ser regulados en una ley de rango inferior a la Constitución; sin embargo, se escriben dentro de la Constitución, porque cada partido político desconfía de los otros. El temor que tienen es que las leyes simples se pueden cambiar por mayoría simple y entonces -al contrario a cambios de la constitución- su consentimiento no sería necesario. Mientras, si incluyen los detalles en la constitución su colaboración en los cambios futuros está de facto asegurada.

A pesar de este riesgo el Legislador debería tener en cuenta que la Constitución es un instrumento jurídico mediante el cual se norman los derechos esenciales de un país y que las leyes de rango inferior son el lugar indicado para normar los detalles.

\section{Limitación gradual de los derechos fundamentales}

En las últimas décadas, pero especialmente en los últimos diez años, Alemania ha visto una gradual limitación de los derechos fundamentales basados en "luchas" contra la criminalidad, contra la defraudación fiscal y últimamente catalizado por la "batalla contra el terror". Una serie de leyes y también de modificaciones de la constitución que parte por parte ha otorgado nuevas facultades de intervención al Estado y sus órganos de seguridad y de investigación a costo de las libertades de los ciudadanos. Ejemplos son la llamada vigilancia secreta en gran escala (großer Lauschangriff), ${ }^{57}$ la autorización del servicio secreto de la República Federal de Alemania (BND) al control computarizado de ciertos datos de un amplio grupo de personas con fines criminológicos (Rasterfahndung), ${ }^{58}$ el uso de GPS para elaborar perfiles de movimiento, ${ }^{59}$ el registro online sistemático y sin sospecha concreta, ${ }^{60}$ las características genéticas, ${ }^{61}$ el almacenamiento de da-

\footnotetext{
54 Hacia la misma dirección LimBACH (2009).

55 Möllers (2009), p. 7: "Nada (en el texto de la Ley Fundamental) se desfasa tan rápidamente como sus innovaciones".

56 Según el artículo 79 inciso 2 de Ley Fundamental para una reforma de la misma se requiere la aprobación de una mayoría de dos tercios de los miembros del Parlamento Federal y dos tercios de los votos del Consejo Federal. Con las constelaciones políticas en los últimos 60 años para poder lograr este quórum siempre serán necesarios la realización de compromisos conjuntos con los otros partidos políticos.

57 Ver Bundesverfassungsgericht (03.03.2004).

58 Ver Bundesverfassungsgericht (14.07.1999).

59 Bundesverfassungsgericht (12.04.2005).

60 Bundesverfassungsgericht (27.02.2008).

61 Bundesverfassungsgericht (14.12.2000).
} 
tos de acopio, ${ }^{62}$ el sistemático de registro automático de placas de matrícula en carreteras, ${ }^{63}$ el control computarizado de ciertos datos de un amplio grupo de personas con fines criminológicos de forma preventiva ${ }^{64}$ o la Ley sobre la Seguridad Aérea ${ }^{65}$ en la cual las fuerzas aéreas fueron legitimadas para derribar aviones secuestrados. ${ }^{60}$

Los defensores de estas medidas glorifican estas nuevas facultades y las consideran esenciales para la seguridad del Estado y de sus ciudadanos. Ellos valoran más la seguridad que la libertad, ${ }^{67}$ un valor por el cual el ser humano tuvo que luchar por siglos. Mientras los oponentes temen, con razón, un estado de vigilancia y el "ciudadano transparente".

Afortunadamente, el Tribunal Constitucional Federal, aunque absolutamente abierto a las necesidades de seguridad, ${ }^{68}$ paró o por lo menos frenó algunos de los proyectos. Lo acontecido entre los parlamentos federales y federados, por un lado, y el Tribunal Constitucional Federal, por el otro lado, ya parece a un juego de ping pong. Los parlamentos aprueban una ley y poco después el Tribunal Constitucional Federal, la declara -por lo menos en parte- inconstitucional. Eso pasó en las últimos 5 años más de 40 veces; ${ }^{69}$ especialmente en lo relacionado con los derechos fundamentales del secreto epistolar, postal y de telecomunicaciones, ${ }^{70}$ de la inviolabilidad del domicilio ${ }^{71}$ y el derecho general de la personalidad ${ }^{72}$ que han sido violados frecuentemente, a pesar de sólo haber transcurrido unos pocos años desde el fin del Servicio (Secreto) de Seguridad del Estado (STASI) en la ex República Democrática de Alemania, mejor conocido como Alemania Oriental. ${ }^{73}$

Hasta el conservativo presidente del Tribunal Constitucional Federal, Hans-Jürgen Papier, ha declarado públicamente, que después del 11 de septiembre 2001 el balance entre seguridad y libertad ha visto un desplazamiento al costo de la libertad. ${ }^{74}$

\section{E. CONCLUSIÓN}

La Ley Fundamental se ha desarrollado y de ser provisoria ha pasado a tener una larga vida. Con sus sesenta años de vigencia ya es una constitución establecida. La Ley

Bundesverfassungsgericht (28.10.2008).

63 Bundesverfassungsgericht (11.03.2008).

64 Bundesverfassungsgericht (04.04.2006).

65 BGBI I 2005, 78, entrando en vigor el 15.01.2005.

66 Declarado inconstitucional por el Tribunal Constitucional Federal, Bundesverfassungsgericht (15.02.2006).

67 Así el Ministro de Interior Federal Wolfgang Schäuble, Frankfurter Allgemeine Zeitung (2009).

68 SACHS (2009), p. 1448 con referencias a sentencias del Tribunal Constitucional Federal.

69 PAPIER (2009).

70 Artículo 10 Ley Fundamental.

1 Artículo 13 Ley Fundamental.

Artículo 2 inciso 1 con artículo 1 Ley Fundamental.

3 SACHS (2009), p. 1448.

74 Papier (2009), parecido DetJen (2009), p. 4. 
Fundamental con su rica dogmática constitucional ha ganado reputación a nivel nacional e internacional. Lo mismo aplica para el Tribunal Constitucional, el máximo guardián de la constitución que ha asegurado una efectiva protección de los derechos fundamentales, que constituyen el núcleo de la Ley Fundamental. El gran logro de la Ley Fundamental en relación a los derechos fundamentales es la garantía al cambio de mentalidad del pueblo alemán, que logró que éste se desarrollara de un pueblo de súbditos a un pueblo de ciudadanos. ${ }^{75}$

Aunque la edad de acceso a una pensión en Alemania es en promedio 63 no hay necesidad de jubilar la Ley Fundamental todavía. A pesar de unas tendencias preocupantes, especialmente la limitación progresiva de los derechos fundamentales, por su concepción abierta la Ley Fundamental está preparada para el futuro. ${ }^{76}$ Sin embargo, con la integración europea su importancia ha disminuido.

\section{BIBLIOGRAFÍA}

BILETZKI, Gregor (1996): “Das Kreuz im Klassenzimmer - Zur bundesverfassungsrechtlichen Zulässigkeit des neuen Art 7 III BayEUG”, en Neue Juristische Wochenschrift (Año 1996), pp. 2633-2634.

BAduRA, Peter (1996): “Das Kreuz im Schulzimmer - Inhalt und Tragweite des Beschlusses des Bundesverfassungsgerichts vom 16-05-1995”, en Bayerische Verwaltungsblätter (Año 1996), pp. 71-77.

BüHLer, Ottmar (1931): La Constitución Alemana de 11 Agosto 1919 (Traducc. José Rovira Armengol, Barcelona, Editorial Labor).

DetJen, Stephan (2009): “Abschied vom Grundgesetz?” en Aus Politik und Zeitgeschichte (Año 2009, Nos 18-19), pp. 3-5.

Frankfurter Allgemeine Zeitung (1998), “Kleine Meldungen”, Artículo del 7.10.1998.

Frankfurter Allgemeine Zeitung (2009), "Wie viele Sicherheitsgesetze überlebt der Rechtsstaat?”, Artículo del 11.03.2009.

HofmanN, Hasso (1989): “Die Grundrechte 1789-1949-1989” en Neue Juristische Wochenschrift (Año 1989), pp. 3177-3187.

Hufen, Friedhelm (1999): "Entstehung und Entwicklung der Grundrechte", en Neue Juristische Wochenschrift (Año 1999), pp. 1504-1510.

KüHNE, Jörg-Detlef (1998): Die Reichsverfassung der Paulskirche: Vorbild und Verwirklichung im späteren deutschen Rechtsleben (Neuwied, Kriftel, Berlin, Editorial Luchterhand).

KunIG, Philip (1990): “Der Reiter im Walde - BVerfG - Beschl v 06-06-89 - 1 BvR 291/ 85”, en Jura (Año 1990), p. 523.

LAMMERT, Norbert (2009): Podiumsdiskussion zum Zustand des Grundgesetzes im 60. Jahr am 21.05.2009, Berlin.

75 LimBach (2009); LAMPRECHT (2009), p. 1454.

76 Möllers (2009), p. 7. 
LAMPRECHT, Rolf (2009): "Vom Untertan zum Bürger - Wie das Bonner Grundgesetz an seinem Karlsruher "Über-Ich" gewachsen ist", en Neue Juristische Wochenschrift (Año 2009), pp. 1454-1457.

LimBACH, Jutta (2009): Podiumsdiskussion zum Zustand des Grundgesetzes im 60. Jahr am 21.05.2009, Berlin.

Möllers, Christoph (2009): "Vom Altern einer Verfassung: 60 Jahre Grundgesetz" en Aus Politik und Zeitgeschichte (Año 2009, Nos 18-19), pp. 5-7.

PAPIER, Hans-Jürgen (2009): Podiumsdiskussion zum Zustand des Grundgesetzes im 60. Jahr am 21.05.2009, Berlin.

Pieroth, Bodo y Schuink, Bernhard (1995): Grundrechte - Staatsrecht II (1 $11^{\text {a }}$ edición, Heidelberg, Editorial C.F. Müller).

RENCK, Ludwig (1996): "Zum rechtlichen Gehalt der Kruzifix-Debatte", en Zeitschrift für Rechtspolitik (Año 1996), pp. 16-20.

RenNert, Klaus (1989): "Das Reiten im Walde - Bemerkungen zu Art 2 I GG", en Neue Juristische Wochenschrift (Año 1989), pp. 3261-3263.

Rottmann, Joachim (1988): La ley fundamental de la República Federal de Alemania: una constitución como resultado de las experiencias históricas (Traducc. Martin Bruggendieck, Santiago de Chile, Corporación de Estudios Liberales).

SACHS, Michael (2009): "Das Grundgesetz in seinem sechsten Jahrzehnt", en Neue Juristische Wochenschrift (Año 2009), pp. 1441-1449.

SMEND, Rudolf (1962): "Festvortrag zur Feier des zehnjährigen Bestehens des Bundesverfassungsgerichts am 26. Januar 1962”, en Das Bundesverfassungsgericht (Karlsruhe), pp. 23-27.

StolleIS, Michael (2000): “Überkreuz Anmerkungen zum Kruzifix-Beschluß (BVerfGE 93, 1-37) und seiner Rezeption”, en Kritische Vierteljahresschrift für Gesetzgebung und Rechtswissenschaft (Año 2000), pp. 376-387.

Zuck, Rüdiger (2006): Das Recht der Verfassungsbeschwerde ( $3^{\text {a }}$ edición, Editorial C.H. Beck, München).

Listado de jurisprudencia

- Amtsgericht Münster (08.12.1992), en Neue Juristische Wochenschrift (Año 1993), p. 1720.

- Bundesverfassungsgericht (26.01.1972) en: Entscheidungen des Bundesverfassungsgerichts - BverfGE, Tomo 32, pp. 296-305.

- Bundesverfassungsgericht (23.05.1980) en: Entscheidungen des Bundesverfassungsgerichts - BverfGE, Tomo 54, pp. 143-148.

- Bundesverfassungsgericht (06.06.1989) en: Entscheidungen des Bundesverfassungsgerichts - BverfGE, Tomo 80, pp. 137-170.

- Bundesverfassungsgericht (17.04.1991) en: Entscheidungen des Bundesverfassungsgerichts - BverfGE, Tomo 84, pp. 34-58.

- Bundesverfassungsgericht (05.02.1993) en Zeitschrift für das gesamte Familienrecht, (Año 1996), pp. 661-664.

- Bundesverfassungsgericht (16.05.1995) en: Entscheidungen des Bundesverfassungsgerichts - BverfGE, Tomo 93, pp. 1-37. 
- Bundesverfassungsgericht (14.07.1999) en: Entscheidungen des Bundesverfassungsgerichts - BverfGE, Tomo 100, pp. 313-403.

- Bundesverfassungsgericht (14.12.2000) en: Entscheidungen des Bundesverfassungsgerichts - BverfGE, Tomo 103, pp. 21-41.

- Bundesverfassungsgericht (03.03.2004) en: Entscheidungen des Bundesverfassungsgerichts - BverfGE, Tomo 109, pp. 279-391.

- Bundesverfassungsgericht (12.04.2005) en: Entscheidungen des Bundesverfassungsgerichts - BverfGE, Tomo 112, pp. 304-321.

- Bundesverfassungsgericht (15.02.2006) en: Entscheidungen des Bundesverfassungsgerichts - BverfGE, Tomo 115, pp. 118-166.

- Bundesverfassungsgericht (04.04.2006) en: Entscheidungen des Bundesverfassungsgerichts - BverfGE, Tomo 115, pp. 320-381.

- Bundesverfassungsgericht (27.02.2008) en: Entscheidungen des Bundesverfassungsgerichts - BverfGE, Tomo 120, pp. 274-350.

- Bundesverfassungsgericht (11.03.2008) en: Entscheidungen des Bundesverfassungsgerichts - BverfGE, Tomo 120, pp. 378-433.

- Bundesverfassungsgericht (28.10.2008) en: Neue Zeitschrift für Verwaltungsrecht (Año 2009), pp. 96-103. 